\title{
Synthetic Cannabinoid Hydroxypentyl Metabolites Retain Efficacy at Human Cannabinoid Receptors
}

\author{
(D) Thomas F. Gamage, Charlotte E. Farquhar, Ryan J. McKinnie, Richard C. Kevin, \\ lain S. McGregor, Mark L. Trudell, Jenny L. Wiley, and Brian F. Thomas \\ RTI International, Research Triangle Park, North Carolina (T.F.G., C.E.F., J.L.W., B.F.T.); Department of Chemistry, University of \\ New Orleans, New Orleans, Louisiana (R.J.M., M.L.T.); and School of Psychology, University of Sydney, Sydney, New South \\ Wales, Australia (R.C.K., I.S.M.)
}

Received October 15, 2018; accepted December 12, 2018

\begin{abstract}
Synthetic cannabinoids (SCs) are novel psychoactive substances that are easily acquired, widely abused as a substitute for cannabis, and associated with cardiotoxicity and seizures. Although the structural bases of these compounds are scaffolds with known affinity and efficacy at the human cannabinoid type-1 receptor $\left(\mathrm{hCB}_{1}\right)$, upon ingestion or inhalation they can be metabolized to multiple chemical entities of unknown pharmacological activity. A large proportion of these metabolites are hydroxylated on the pentyl chain, a key substituent that determines receptor affinity and selectivity. Thus, the pharmacology of SC metabolites may be an important component in understanding the in vivo effects of SCs. We examined nine SCs (AB-PINACA, 5F-AB-PINACA, ADB/MDMB-PINACA, 5F-ADB, 5F-CUMYL-PINACA, AMB-PINACA, 5F-AMB, APINACA, and 5F-APINACA) and their hydroxypentyl (either $4-\mathrm{OH}$ or $5-\mathrm{OH}$ )
\end{abstract}

metabolites in $\left[{ }^{3} \mathrm{H}\right] \mathrm{CP} 55,940$ receptor binding and the $\left[{ }^{35} \mathrm{~S}\right]$ GTP $\gamma \mathrm{S}$ functional assay to determine the extent to which these metabolites retain activity at cannabinoid receptors. All of the SCs tested exhibited high affinity $(<10 \mathrm{nM})$ and efficacy for $\mathrm{hCB}_{1}$ and $\mathrm{hCB}_{2}$. The majority of the hydroxypentyl metabolites retained full efficacy at $\mathrm{hCB}_{1}$ and $\mathrm{hCB}_{2}$, albeit with reduced affinity and potency, and exhibited greater binding selectivity for $\mathrm{hCB}_{2}$. These data suggest that phase I metabolites may be contributing to the in vivo pharmacology and toxicology of abused SCs. Considering this and previous reports demonstrating that metabolites retain efficacy at the $\mathrm{hCB}_{1}$ receptor, the full pharmacokinetic profiles of the parent compounds and their metabolites need to be considered in terms of the pharmacological effects and time course associated with these drugs.

\section{Introduction}

Despite the efforts of governments and law enforcement agencies to curb the sale and use of novel psychoactive substances (NPS), the method of reactionary drug scheduling has been met with an unrelenting effort by clandestine chemists to modify chemical structures in order to circumvent the law (Trecki et al., 2015). Among the NPS, synthetic cannabinoids have emerged as a robust market probably as a result of: 1) the widespread use of cannabis, 2) lack of knowledge or consideration regarding the safety of synthetic cannabinoid products, and 3) its potential to serve as a cannabis replacement to avoid detection in drug testing (Every-Palmer, 2011; BerryCabán et al., 2012; Gunderson et al., 2012; Vandrey et al., 2012).

This work was supported by the National Institutes of Health National Institute of Drug Abuse [Grants R01 DA003672, R01 DA040460, K01 DA045752]

https://doi.org/10.1124/jpet.118.254425.
Historically, synthetic cannabinoids were developed for pharmacological interrogation of biologic systems (Wiley et al., 2011), including the study of their cognate $\mathrm{G}_{\mathrm{i} / \mathrm{o}}$ proteincoupled receptors and cannabinoid type $1\left(\mathrm{CB}_{1}\right)$ and type-2 receptors $\left(\mathrm{CB}_{2}\right)$ [for reviews see Svízenská et al. (2008), Kendall and Yudowski (2017), Thomas, 2017)]. Therefore, little is known regarding their toxicological effects and how these relate to either the parent compound, its thermal degradants (Thomas et al., 2017), or its metabolites. Further, a focus on the metabolic fate of these compounds (Fantegrossi et al., 2014) has only recently become the subject of scientific inquiry as reports of human use and adverse health events become more prevalent, and analytical methods for the detection of synthetic cannabinoid use are developed.

Although the majority of abused synthetic cannabinoids are high affinity and high efficacy cannabinoid receptor agonists, only a few studies have examined the pharmacology of their metabolites (Brents et al., 2011, 2012; Chimalakonda et al., 2012; Rajasekaran et al., 2013; Cannaert et al., 2016, 2017;

ABBREVIATIONS: AM2201, 1-[(5-fluoropentyl)-1H-indol-3-yl]-(naphthalen-1-yl)methanone; GDP, guanosine diphosphate [(2R,3S,4R,5R)-5-(2amino-6-oxo-3H-purin-9-yl)-3,4-dihydroxyoxolan-2-yl]methyl phosphono hydrogen phosphate; GTP $\gamma \mathrm{S}$, [(2S,3R,4S,5S)-5-(2-amino-6-oxo-3Hpurin-9-yl)-3,4-dihydroxyoxolan-2-yl]methyl dihydroxyphosphinothioyl hydrogen phosphate; hCB ${ }_{1}$, human cannabinoid type-1 receptor; hCB ${ }_{2}$, human cannabinoid type-2 receptor; $\left.{ }^{3} \mathrm{H}\right] \mathrm{SR} 141716$ (5-(4-chlorophenyl)-1-(2, 4-dichlorophenyl)-4-methyl- $\mathrm{N}$-1-piperidinyl-1H-pyrazole-3-carboxamide; HEK293, human embryonic kidney-293 cells; JWH-018, naphthalen-1-yl-(1-pentylindol-3-yl)methanone; JWH-073, naphthalen-1-yl-(1butylindol-3-yl)methanone; MN-18, $N$-(naphthalen-1-yl)-1-pentyl-1H-indazole-3-carboxamide; $\Delta^{9}-\mathrm{THC},[(-)-(6 a R, 10 a R)-6,6,9-$ trimethyl-3-pentyl6a, 7,8,10a-tetrahydro-6H-benzo(c)chromen-1-ol]. 
Longworth et al., 2017). Data suggest that seizure activity of the abused synthetic cannabinoids JWH-018 (Malyshevskaya et al., 2017), and AM2201 (Funada and Takebayashi-Ohsawa, 2018) is $\mathrm{CB}_{1}$-dependent; thus, metabolites with activity at these receptors may contribute to the observed pharmacology and toxicity associated with synthetic cannabinoids.

Synthetic cannabinoids are metabolized via cytochrome P450 enzymes, resulting in phase I hydroxylated metabolites (Tai and Fantegrossi, 2017). An alkyl side chain, when present, appears as if it would undergo hydroxylation at several positions. Compounds fluorinated at the 5-position are also susceptible to oxidative defluorination and hydroxylation (Wohlfarth et al., 2015; Kusano et al., 2018). Metabolism of CUMYL-PICA as assessed by rat and human hepatocyte incubations revealed 18 metabolites, with hydroxylation at the terminal position of the pentyl chain being the greatest in abundance (Kevin et al., 2017). Analysis of 5F-MN-18 metabolism by human hepatocytes also revealed terminal hydroxylation of the pentyl chain as the most abundant metabolite (Carlier et al., 2018). Metabolism of AB-PINACA by human liver microsomes suggested hydroxylation occurred primarily on the pentyl chain (Takayama et al., 2014). Importantly, hydroxypentyl metabolites detected from metabolism experiments with pooled human liver microsomes were also detected in urine samples from two individuals who had been suspected of consuming AB-PINACA (Wohlfarth et al., 2015), demonstrating that these metabolic products occur in humans. $5 \mathrm{~F}$ ADB/5F-MDMB-PINACA, which was implicated in four deaths in Japan of people who had been in possession of a product called "Heart Shock BLACK" (Usui et al., 2018) and others
(Hasegawa et al., 2015; Kusano et al., 2018), can also be metabolized to form hydroxylated metabolites, including at the 5 position of the pentyl chain (Barcelo et al., 2017). Metabolism of other synthetic cannabinoids, including AMB, 5F-AMB (Andersson et al., 2016), and EG-018 (Mogler et al., 2018), have been reported to lead to hydroxypentyl metabolites.

The $n$-pentyl side chain is a common feature of phyto- and endocannabinoids and is a key determinant of affinity, potency, and selectivity at cannabinoid receptors [for review, see Thakur et al. (2005)]. Considering the importance of the alkyl substituent and its likelihood to undergo metabolic hydroxylation, pharmacological impact of this biotransformation on abused synthetic cannabinoids is an important consideration regarding the in vivo effects of these compounds. Therefore, synthetic cannabinoids AB-PINACA, 5F-AB-PINACA, ADB/ MDMB-PINACA，5F-ADB/5F-MDMB-PINACA，5F-AMB/5FAMB-PINACA, AMB/AMB-PINACA, APINACA/AKB-48, 5F-APINACA/5F-AKB-48, 5F-CUMYL-PINACA and their hydroxylated metabolites (at the 4- or 5- position of the pentyl chain) were synthesized (McKinnie et al., 2018; unpublished) and tested in studies of receptor affinity and function using human $\mathrm{CB}_{1}\left(\mathrm{hCB}_{1}\right)$ and human $\mathrm{CB}_{2}\left(\mathrm{hCB}_{2}\right)$ expressing human embryonic kidney (HEK293) cells. Pharmacological properties were then compared between the metabolite and parent to determine changes regarding the ligand's affinity, potency and efficacy. These systematic studies were conducted to determine what impact pentyl hydroxylation would have across a range of abused synthetic cannabinoid structures (Fig. 1).

\section{AB-PINACA
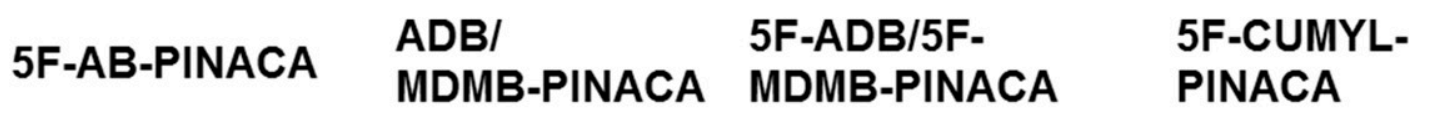
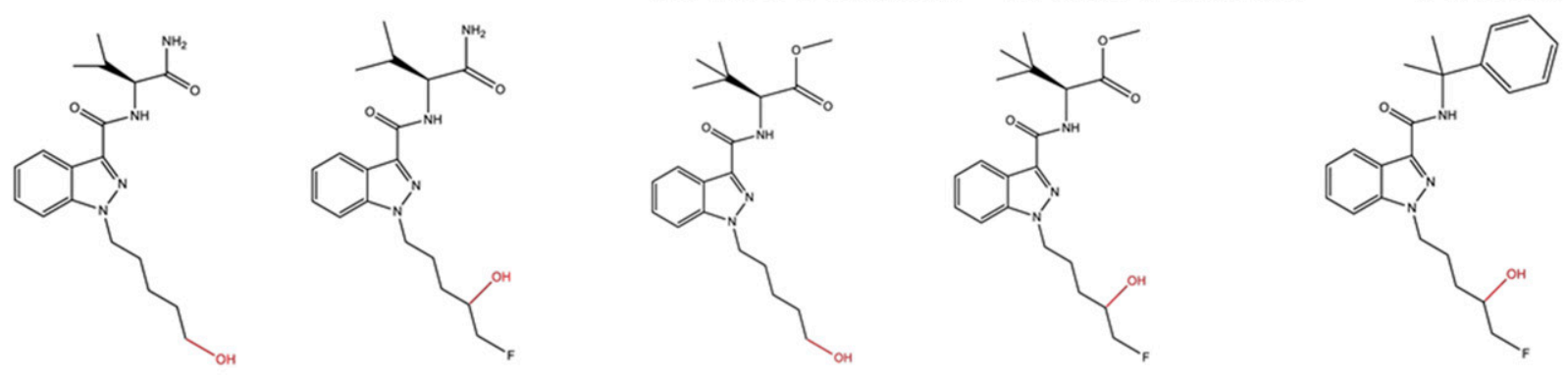
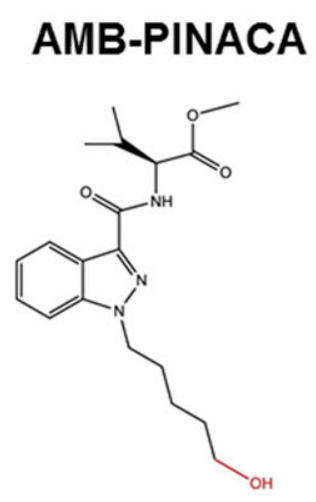
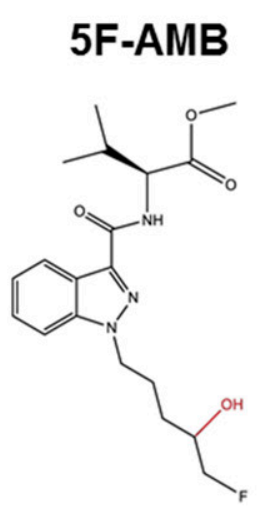

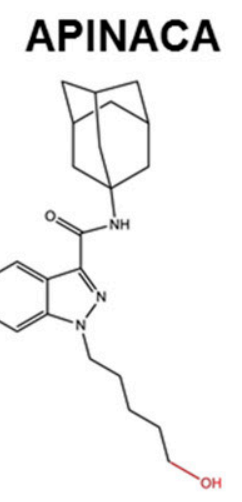

5F-APINACA

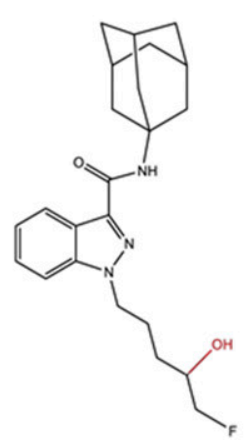

Fig. 1. Structures of synthetic cannabinoids and location of metabolite hydroxy group depicted in red. 


\section{Materials and Methods}

Chemicals. For these studies, $\Delta^{9}$-THC $[(-)-(6 \mathrm{a} R, 10 \mathrm{a} R)-6,6,9-$ trimethyl-3-pentyl-6a,7,8,10a-tetrahydro-6H-benzo(c)chromen-1-ol], CP55,940 (5-(1,1-dimethylheptyl)-2-[(1R,2R,5R)-5-hydroxy-2-(3hydroxypropyl)cyclohexyl]-phenol), [ $\left.{ }^{3} \mathrm{H}\right] \mathrm{SR} 141716$ (5-(4-chlorophenyl)1-(2,4-dichlorophenyl)-4-methyl- $N$-1-piperidinyl- $1 H$-pyrazole-3carboxamide; $24 \mathrm{Ci} / \mathrm{mmol}),\left[{ }^{3} \mathrm{H}\right] \mathrm{CP} 55,940(81.1 \mathrm{Ci} / \mathrm{mmol})$ and unlabeled SR141716 were obtained from the National Institute on Drug Abuse (NIDA; North Bethesda, MD) and dissolved in absolute ethanol. All synthetic cannabinoids were synthesized in the laboratory of Dr. M. L. Trudell and were dissolved in 100\% dimethyl sulfoxide. All drugs were stored at $-80^{\circ} \mathrm{C}$ as $10 \mathrm{mM}$ stocks. Guanosine diphosphate (GDP; [(2R,3S,4R,5R)-5-(2-amino-6-oxo-3H-purin-9-yl)-3,4-dihydroxyoxolan2-yl]methyl phosphono hydrogen phosphate; MilliporeSigma, St. Louis, MO), unlabeled guanosine 5 '-O-[gamma-thio]triphosphate (GTP $\gamma \mathrm{S}$; [(2S,3R,4S,5S)-5-(2-amino-6-oxo-3H-purin-9-yl)-3,4-dihydroxyoxolan-2-yl]methyl dihydroxyphosphinothioyl hydrogen phosphate; MilliporeSigma), and $\left[{ }^{35} \mathrm{~S}\right] \mathrm{GTP} \gamma \mathrm{S}(1250 \mathrm{Ci} / \mathrm{mmol}$; PerkinElmer, Waltham, MA) were dissolved in distilled water, aliquoted and stored at $-80^{\circ} \mathrm{C}$.

Receptor Binding and Agonist-Stimulated $\left[{ }^{35} \mathbf{S}\right]$ GTP $\gamma \mathbf{S}$ Binding. HEK293 cells stably expressing either the human $\mathrm{CB}_{1}$ or $\mathrm{CB}_{2}$ receptor (PerkinElmer) were grown in Dulbecco's modified Eagle's medium/F12 (10-092-CV; Corning Cellgro, Manassas, VA) with 10\% fetal bovine serum (FBS-BBT; Rocky Mountain Biological Laboratory, Crested Butte, CO), $50 \mathrm{IU} / \mathrm{ml}$ penicillin/streptomycin (Thermo Fisher Scientific, Waltham, MA) in multilayer flasks to $90 \%$ confluence. Cells were detached using $1 \mathrm{mM}$ EDTA in phosphate buffered saline (PBS; MilliporeSigma), pelleted in PBS at 200g for 6 minutes, then suspended in fractionation buffer ( $50 \mathrm{mM}$ Tris base, $320 \mathrm{mM}$ sucrose, $1 \mathrm{mM}$ EGTA, $\mathrm{pH}$ 7.4), and homogenized by dounce. Cell homogenates were centrifuged at $1600 \mathrm{~g}$ for 10 minutes at $4^{\circ} \mathrm{C}$, the supernatant was collected, and the pellet was homogenized again and centrifuged at $1600 \mathrm{~g}$ for 10 minutes at $4^{\circ} \mathrm{C}$. The supernatants were pooled and spun at $40,000 \mathrm{~g}$ for 1 hour at $4^{\circ} \mathrm{C}$ resulting in a $\mathrm{P} 2$ pellet. The $\mathrm{P} 2$ pellet was resuspended in membrane buffer ( $50 \mathrm{mM}$ Tris base, $1 \mathrm{mM}$ EGTA, $3 \mathrm{mM}$ $\mathrm{MgCl}_{2}, \mathrm{pH}$ 7.4), the protein amount was quantified by the Bradford method, and the membrane preparations were diluted to $1 \mathrm{mg} / \mathrm{ml}$, snapfrozen in liquid nitrogen, and stored at $-80^{\circ} \mathrm{C}$ until the day of the experiment. For receptor binding, reactions were carried out in assay buffer [50 mM Tris base, $125 \mathrm{mM} \mathrm{NaCl}, 3 \mathrm{mM} \mathrm{MgCl}_{2}$, and $6.25 \mathrm{mg} / \mathrm{ml}$ of bovine serum albumin (BSA)] into which membranes (10 $\mu \mathrm{g}$ protein) were added in a volume of $100 \mu \mathrm{l}$, bringing the final reaction volume to $500 \mu \mathrm{l}$. This resulted in a final assay buffer containing $50 \mathrm{mM}$ Tris base, $100 \mathrm{mM} \mathrm{NaCl}, 3 \mathrm{mM} \mathrm{MgCl}_{2}, 0.2 \mathrm{mM}$ EGTA and $5 \mathrm{mg} / \mathrm{ml} \mathrm{BSA}$. Reactions were carried out for 90 minutes at $30^{\circ} \mathrm{C}$ with $1 \mathrm{nM}\left[{ }^{3} \mathrm{H}\right] \mathrm{CP} 55,940\left(\mathrm{hCB}_{1}\right.$ $\mathrm{K}_{\mathrm{d}}=1.2 \mathrm{nM} ; \mathrm{hCB}_{2} \mathrm{~K}_{\mathrm{d}}=1.2 \mathrm{nM}$ ) and varying concentrations of synthetic cannabinoids. $\left[{ }^{3} \mathrm{H}\right] \mathrm{CP} 55,940$ saturation binding was conducted prior to competition binding experiments to determine $\mathrm{K}_{\mathrm{d}}$ values for CP55,940 at $\mathrm{hCB}_{1}$ and $\mathrm{hCB}_{2}$ receptors using nominal concentrations of 0.01 , $0.032,0.1,0.32,0.6,1,3.2$, and $6 \mathrm{nM}$. Amount of radioligand added for each experiment was determined by pipetting $50 \mu \mathrm{l}$ of each nominal concentration stock, adding $20 \mathrm{ml}$ of Ultima Gold scintillation cocktail, and analyzing on a Packard TriCarb 2300TR scintillation counter. Nonspecific binding was determined by addition of excess cold ligand (1 $\mu \mathrm{M})$. Total bound $\left[{ }^{3} \mathrm{H}\right] \mathrm{CP} 55,940$ was less than $10 \%$ of total added (minimal ligand depletion). For receptor signaling, membranes (10 $\mu \mathrm{g}$ protein) were incubated for 60 minutes at $30^{\circ} \mathrm{C}$ with $30 \mu \mathrm{M}$ GDP and $0.10-0.12 \mathrm{nM}\left[{ }^{35} \mathrm{~S}\right] \mathrm{GTP} \gamma \mathrm{S}$, and nonspecific binding was determined by adding $30 \mu \mathrm{M}$ unlabeled GTP $\gamma \mathrm{S}$. Binding was terminated by vacuum filtration through a PerkinElmer GF/C filter plate using a PerkinElmer FilterMate.

Data Analysis. All data were analyzed using GraphPad Prism 6.0 (GraphPad Software, San Diego, CA). $\left[{ }^{35} \mathrm{~S}\right] \mathrm{GTP} \gamma \mathrm{S}$ data were normalized to maximal stimulation by CP55,940 and were fit to three parameter nonlinear regression. $\mathrm{pEC}_{50}$ and $\mathrm{E}_{\max }$ values were considered significantly different when $95 \%$ confidence intervals (CI) did not overlap. For saturation binding, data were fit to "One site - Specific Binding" using GraphPad Prism to determine radioligand $\mathrm{K}_{\mathrm{d}}$. For competition radioligand binding data, $\mathrm{K}_{\mathrm{i}}$ values to displace $1 \mathrm{nM}\left[{ }^{3} \mathrm{H}\right]$ SR141716 for $\mathrm{hCB}_{1}$ or $1 \mathrm{nM}\left[{ }^{3} \mathrm{H}\right] \mathrm{CP} 55,940$ were determined using "One site - fit $\mathrm{K}_{\mathrm{i}}$ in Prism 6.0. Each data point represents the mean and S.E. of at least $N=3$ experiments performed in duplicate.

\section{Results}

Receptor Binding. All compounds tested exhibited affinity for both $\mathrm{hCB}_{1}$ and $\mathrm{hCB}_{2}$ receptors as determined by displacement binding of the high-affinity cannabinoid agonist $\left[{ }^{3} \mathrm{H}\right] \mathrm{CP} 55,940$ (Fig. 2; Table 1). The control compound, unlabeled CP55,940, exhibited a $\mathrm{K}_{\mathrm{i}}$ value of $1.25 \mathrm{nM}$ at $\mathrm{hCB}_{1}$ and $1.15 \mathrm{nM}$ at $\mathrm{hCB}_{2}$, consistent with the $\mathrm{K}_{\mathrm{d}}$ values of $1.26 \pm 0.399$ $\mathrm{nM}$ at $\mathrm{hCB}_{1}$ and $1.24 \pm 0.377 \mathrm{nM}$ at $\mathrm{hCB}_{2}$ determined from separate $\left[{ }^{3} \mathrm{H}\right] \mathrm{CP} 55,940$ saturation binding experiments (data not shown). Parent compounds all exhibited high affinity at $\mathrm{hCB}_{1}$ receptors in the nanomolar range, with a few compounds (i.e., ADB, 5F-ADB, and 5F-CUMYL-PINACA) exhibiting subnanomolar affinities (Fig. 2, A-C). Rank order affinities (high to low) for the parent compounds at $\mathrm{hCB}_{1}$ were: $5 \mathrm{~F}-\mathrm{CUMYL}$ PINACA $=5 \mathrm{~F}-\mathrm{ADB}=\mathrm{ADB}>5 \mathrm{~F}$-APINACA $>$ AMB-PINACA $=5 \mathrm{~F}$-AMB-PINACA $=5 \mathrm{~F}$-AB-PINACA $=$ AB-PINACA $=$ APINACA. Parent compounds all exhibited high affinity at $\mathrm{hCB}_{2}$ receptors in the nanomolar range, with a few compounds (i.e., ADB, 5F-ADB, and 5F-APINACA) exhibiting subnanomolar affinities (Fig. 2, D-F). Rank order affinities for the parent compounds at $\mathrm{hCB}_{2}$ were: $5 \mathrm{~F}$-APINACA $=\mathrm{ADB}=5 \mathrm{~F}-\mathrm{ADB}>$ 5F-CUMYL-PINACA $=$ APINACA $=$ AB-PINACA $=$ AMBPINACA $=5$ F-AMB-PINACA $=5$ F-AB-PINACA.

Synthetic cannabinoid hydroxypentyl metabolites all displaced $\left[{ }^{3} \mathrm{H}\right] \mathrm{CP} 55,940$ binding but exhibited marked reductions in affinity as determined by calculated $\mathrm{K}_{\mathrm{i}}$ values from displacement curves. Changes in affinity for the majority of metabolites tested varied from 10- to 80-fold lower than the parent compounds for both receptors with the exception of AB-PINACA, which exhibited the largest reduction in affinity for $\mathrm{hCB}_{1}$ and $\mathrm{hCB}_{2}$, approximately 260 - and 110-fold respectively. There was a positive correlation for $\mathrm{K}_{\mathrm{i}}$ selectivity ratios between the parent and metabolite $(\mathrm{r}(\mathbf{9})=0.982, P<0.0001)$, suggesting that hydroxylation had little or no effect on receptor binding selectivity. Selectivity for $h_{C B}$ versus $h \mathrm{hB}_{2}$ was modest for all parent compounds tested, with 5F-CUMYLPINACA and 5F-APINACA exhibiting the largest folddifference in selectivity, a 5-fold greater affinity for $\mathrm{hCB}_{1}$ and $\mathrm{hCB}_{2}$, respectively. Pentyl-hydroxylation appeared to affect affinity at $\mathrm{hCB}_{1}$ receptors to a greater extent than at $\mathrm{hCB}_{2}$ receptors, as fold-changes in affinity for metabolite/parent were mostly greater for $\mathrm{hCB}_{1}$ than $\mathrm{hCB}_{2}$. In other words, in addition to reducing affinity, hydroxylation produced a modest increase in selectivity for $\mathrm{hCB}_{2}$ over $\mathrm{hCB}_{1}$ for all compounds except for 5F-APINACA, which retained a 5 -fold greater affinity for $\mathrm{hCB}_{2}$ following hydroxylation. AMB-PINACA, 5F-ADB, and ADB exhibited the greatest disparity in effects on $\mathrm{hCB}_{1}$ versus $\mathrm{hCB}_{2}$ affinity with approximate 6-, 4-, and 3.5-fold differences in relative shifts in $\mathrm{hCB}_{1}$ affinity compared with $\mathrm{hCB}_{2}$, respectively (determined by dividing the $\mathrm{hCB}_{1} \mathrm{~K}_{\mathrm{i}}$ metabolite/parent ratio with that of the $\mathrm{hCB}_{2}$ ratio).

Agonist-Stimulated $\left[{ }^{35} \mathrm{~S}\right] \mathrm{GTP} \gamma \mathrm{S}$ Binding in $\mathrm{hCB}_{1 \text { - }}$ and $h_{C B}$-Expressing HEK293 Cell Membranes. Synthetic cannabinoid parent and metabolites all exhibited 
A

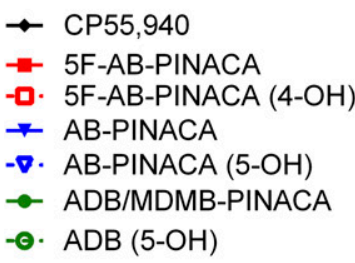

$\mathrm{hCB}_{1}$

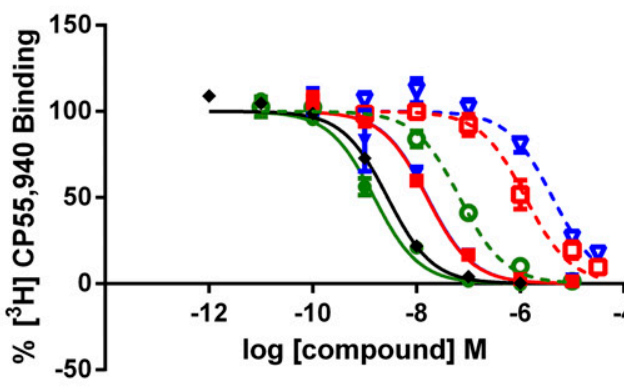

$\mathrm{hCB} \mathrm{B}_{2}$

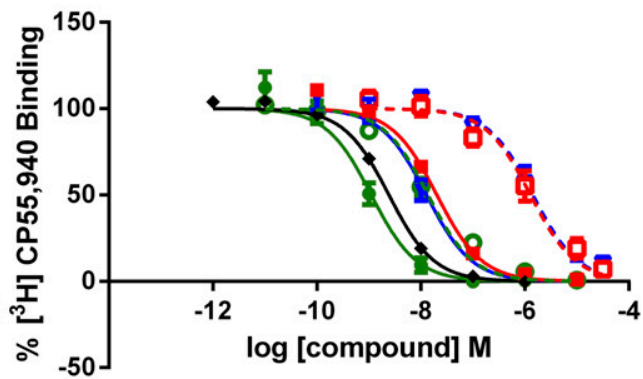

B

E
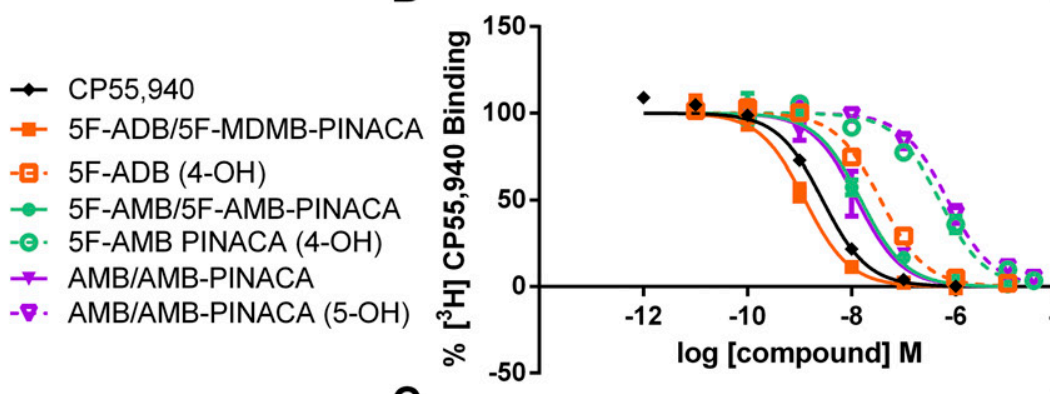

CP55,940

5F-APINACA

-๑. 5F-APINACA (4-OH)

$\rightarrow$ APINACA/AKB 48

๑. APINACA/AKB $48(5-\mathrm{OH})$

* 5F-CUMYL-PINACA

$-\nabla \cdot 5$ F-CUMYL-PINACA (4-OH)

\section{C}
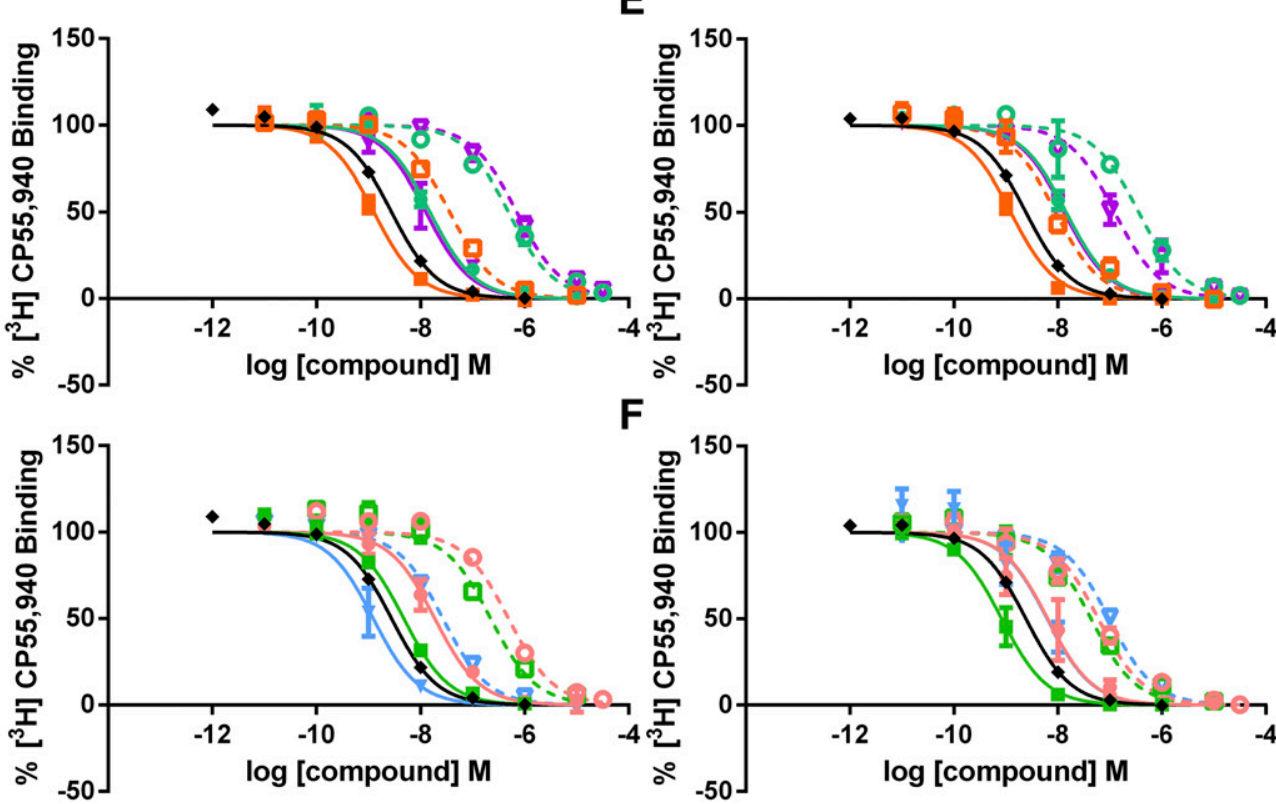

F

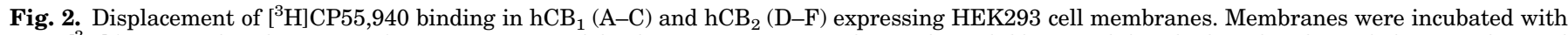

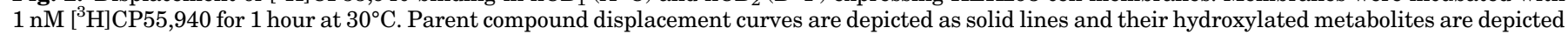

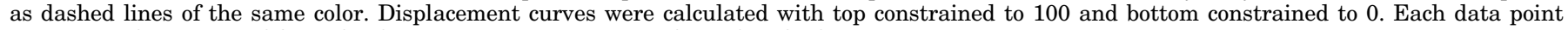
represents the mean and S.E. of at least $N=3$ experiments performed in duplicate.

similar efficacy as CP55,940 $\left(\mathrm{E}_{\max }=94.5 \pm 3.23\right)$ at $\mathrm{hCB}_{1}$ receptors except for AB-PINACA, which exhibited greater efficacy $\left(\mathrm{E}_{\max }=122 \pm 7\right)$ than CP55,940 as determined by nonoverlapping 95\% confidence intervals (Fig. 3, A-C; Table 2). Likewise, all compounds exhibited similar efficacy compared with $\mathrm{CP55,940}\left(\mathrm{E}_{\max }=92.4 \pm 3.27\right)$ at $\mathrm{hCB}_{2}$ receptors except for AMB-PINACA $\left(\mathrm{E}_{\max }=131 \pm 11.4\right)$, which exhibited greater efficacy than CP55,940 (Fig. 3, D-F; Table 3). Over half of the parent compounds tested exhibited subnanomolar potency at $\mathrm{hCB}_{1}$ receptors including ADB, 5F-ADB，5F-APINACA，5F-CUMYL-PINACA, and AMBPINACA. The remaining parent compounds, 5F-AMB, 5F-AB-PINACA, APINACA, and AB-PINACA exhibited potencies in the nanomolar range.

Consistent with the receptor binding data in which metabolites exhibited reduced affinity for both receptors, metabolites also exhibited reduced potency to stimulate $\left[{ }^{35} \mathrm{~S}\right] \mathrm{GTP} \gamma \mathrm{S}$ binding in both $\mathrm{hCB}_{1}$ and $\mathrm{hCB}_{2}$ membranes (Fig. 3; Tables 2 and 3). Most synthetic cannabinoid parent compounds exhibited marginal selectivity for either receptor, with an approximate 2-fold difference in $\mathrm{EC}_{50}$ values on average. $5 \mathrm{~F}$-AB-PINACA, $5 \mathrm{~F}$-ADB, and AMB-PINACA exhibited roughly 2-fold greater potency at $\mathrm{hCB}_{1}$ versus $\mathrm{hCB}_{2}$, whereas AB-PINACA and 5F-APINACA exhibited approximately 2- to 3-fold greater potency at $\mathrm{hCB}_{2}$ versus $\mathrm{hCB}_{1}$. APINACA/AKB48 and 5F-CUMYL-PINACA had slightly greater selectivity with 10 -fold greater potency at $\mathrm{hCB}_{2}$ versus $\mathrm{hCB}_{1}$. Notably, $5 \mathrm{~F}$-CUMYL-PINACA was very potent at stimulating $\mathrm{hCB}_{2}$ receptors, with an $\mathrm{EC}_{50}$ value of $63 \mathrm{pM}$.

Although hydroxylation of the pentyl chain appeared to produce a greater reduction of potency at $\mathrm{hCB}_{2}$ receptors $(123 \pm 138.1)$ versus $h_{C B}$ receptors $(54.4 \pm 47.5)$, as determined by averaging the fold-changes in potency at $\mathrm{hCB}_{1}$ and $\mathrm{hCB}_{2}$ (Tables 2 and 3 ), this was not significant $(\mathrm{t}=1.42$, $P=0.18$ ). Changes in potency following hydroxylation did vary, as shifts toward $\mathrm{hCB}_{1}$ or $\mathrm{hCB}_{2}$ selectivity were split almost equally (Table 3), with ratios of fold change for $\mathrm{hCB}_{2}$ over $\mathrm{hCB}_{1}$ being less than 1 (i.e., greater reduction in potency for $\mathrm{hCB}_{1}$ ) for ADB (0.7), 5F-ADB (0.1), and AMB-PINACA (0.2) and greater than 1 (i.e., greater reduction in potency for $\mathrm{hCB}_{2}$ ) for AB-PINACA (3.5), 5F-AMB-PINACA (6.4), 5F-APINACA (3.3), APINACA/AKB48 (2.3), and 5F-CUMYL-PINACA (15.1). 5F-AB-PINACA exhibited no change in selectivity (1.0).

In contrast to the binding data in which hydroxylation predominantly increased selectivity for $\mathrm{hCB}_{2}$ over $\mathrm{hCB}_{1}$, there was no correlation between the $\mathrm{hCB}_{2} / \mathrm{hCB}_{1} \mathrm{EC}_{50}$ selectivity ratio for parent and metabolite $(\mathrm{r}=-0.135, P=0.73)$, 
TABLE 1

$\left[{ }^{3} \mathrm{H}\right] \mathrm{CP} 55,940$ competition binding affinities of synthetic cannabinoids and metabolites to $\mathrm{hCB}_{1}$ and $\mathrm{hCB}_{2}$ receptors

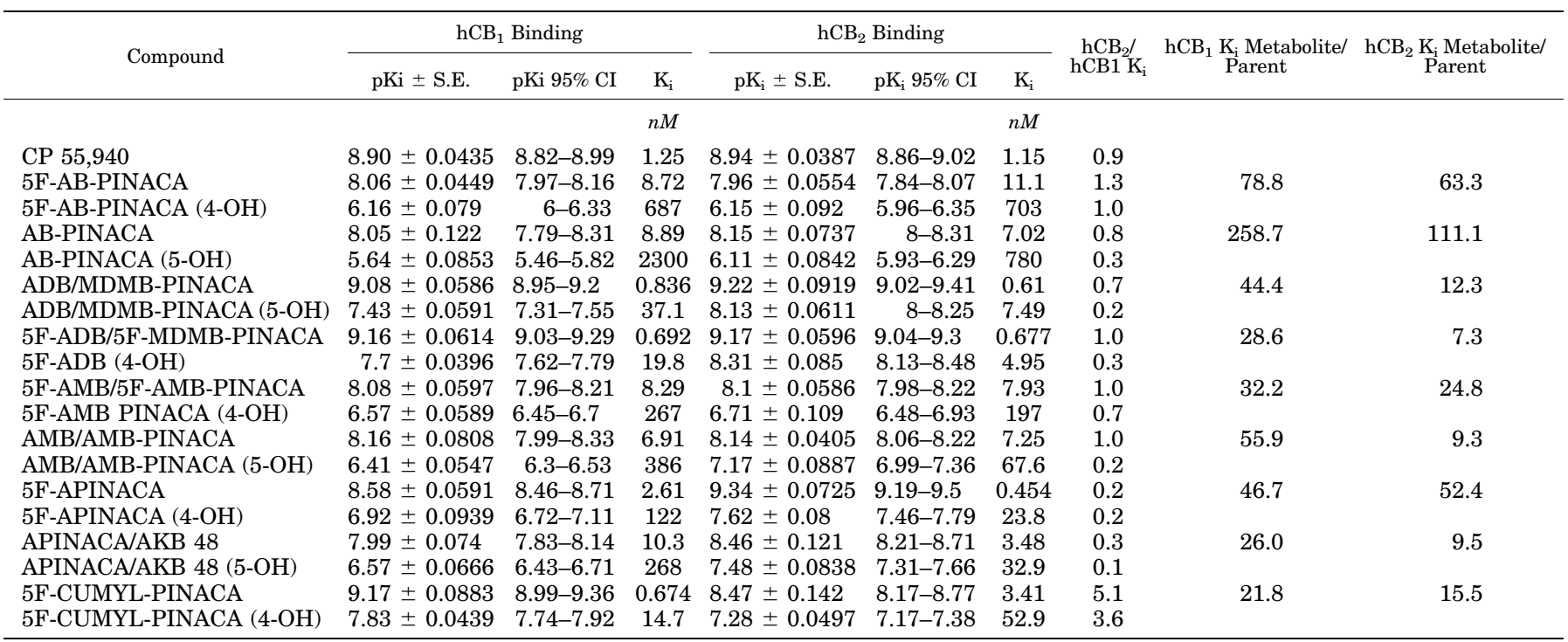

meaning the parent compound's selectivity did not predict that of the metabolite (Table 2). In addition, there was no correlation between binding and functional data when $\mathrm{hCB}_{2} /$ $\mathrm{hCB}_{1}$ selectivity ratios were calculated for metabolite/parent $(\mathrm{r}(9)=0.412, P=0.271)$; i.e., the fold change in selectivity following hydroxylation did not correlate between $\mathrm{K}_{\mathrm{i}}$ and $\mathrm{EC}_{50}$ values, suggesting that relative shifts in binding selectivity did not translate into shifts in relative potencies. Indeed, $\mathrm{hCB}_{2} / \mathrm{hCB}_{1} \mathrm{EC}_{50}$ selectivity ratios appeared to flip for the hydroxylated metabolite for a number of compounds (Table 2), including 5F-ADB (parent ratio: 1.6, metabolite ratio: 0.2), 5F-AMB (parent ratio: 0.2, metabolite ratio: 1.3), AMBPINACA (parent ratio: 2.1, metabolite ratio: 0.5 ), $5 \mathrm{~F}$ APINACA (parent ratio: 0.4, metabolite ratio: 1.4 ), and 5FCUMYL-PINACA (parent ratio: 0.1, metabolite ratio: 2.2 ). In contrast, binding selectivity $\left(\mathrm{hCB}_{2} / \mathrm{hCB}_{1}\right)$ ratios (Table 1 ) were: $5 \mathrm{~F}-\mathrm{ADB}$ (parent ratio: 1.0 , metabolite ratio: 0.3 ), $5 \mathrm{~F}$ AMB (parent ratio: 1.0, metabolite ratio: 0.7), AMB-PINACA (parent ratio: 1.0, metabolite ratio: 0.2), 5F-APINACA (parent ratio: 0.2 , metabolite ratio: 0.2 ), and 5F-CUMYL-PINACA (parent ratio: 5.1, metabolite ratio: 3.6 ).

\section{Discussion}

A large proportion of metabolic products for synthetic cannabinoids are hydroxylated on the alkyl chain when it is present (Takayama et al., 2014; Castaneto et al., 2015; Andersson et al., 2016; Berg et al., 2016; Barcelo et al., 2017; Richter et al., 2017; Carlier et al., 2018). To examine the potential for these products to contribute to the overall pharmacological response in humans, we examined nine abused synthetic cannabinoids and their hydroxypentyl metabolites. These compounds were assessed for their pharmacological properties at the human $\mathrm{CB}_{1}$ and $\mathrm{CB}_{2}$ receptors to determine their binding affinities and their potencies and efficacies to stimulate receptor activation as measured by $\left[{ }^{35} \mathrm{~S}\right]$ GTP $\gamma \mathrm{S}$ binding.

The parent compounds all exhibited high affinity binding to both cannabinoid receptors, with $\mathrm{K}_{\mathrm{i}}$ values in the nanomolar to subnanomolar range, which were lower than the previously determined $\mathrm{K}_{\mathrm{i}}$ values for $\mathrm{THC}$ of 16 and $23 \mathrm{nM}$ at $\mathrm{hCB}_{1}$ and $\mathrm{hCB}_{2}$, respectively (Gamage et al., 2018). This is consistent with previous reports for these and other synthetic cannabinoids, which typically exhibit very high affinity for both receptors [for review, see Banister and Connor (2018)]. Notably, all the hydroxypentyl metabolites exhibited reductions in binding affinity for both cannabinoid receptors. A trend for the metabolites to exhibit a greater reduction in affinity for $\mathrm{hCB}_{1}$ versus $\mathrm{hCB}_{2}$ was observed, as most $h \mathrm{hCB}_{2} /$ $\mathrm{hCB}_{1} \mathrm{~K}_{\mathrm{i}}$ ratios went down, except for $5 \mathrm{~F}$-APINACA, which did not differ from its 5-OH metabolite. Most metabolites retained the same magnitude of efficacy as the parent compounds, except for AMB-PINACA, which had a small but significant reduction in calculated $\mathrm{E}_{\max }$ for $\mathrm{hCB}_{2}$ receptors. These data suggest that even though the pharmacokinetic profiles of synthetic cannabinoids may reflect reductions in levels of the parent compound, the potential contribution of metabolites to the observed behavioral and physiologic effects cannot be discounted.

JWH-018 (Brents et al., 2011; Chimalakonda et al., 2012) and JWH-073 (Brents et al., 2012) were reported to exhibit similar reductions in $\mathrm{CB}_{1}$ binding affinity following hydroxylation at the 5- position of the pentyl chain. Hydroxylation at the 4- position of AM-2201 also reduced its affinity at $\mathrm{CB}_{1}$ (Chimalakonda et al., 2012). The JWH-018 (5-OH) metabolite was reported to exhibit a 20- (Brents et al., 2011) to 27-fold (Chimalakonda et al., 2012) reduction in affinity for $\mathrm{CB}_{1}$ compared with the parent (Brents et al., 2011), and the JWH$073(5-\mathrm{OH})$ metabolite exhibited an approximately 17 -fold reduction in affinity (Brents et al., 2012). These data are consistent with the present study, which observed 26- to 56 -fold reductions in affinity at $\mathrm{hCB}_{1}$ receptors for most of the 5-OH metabolites except for AB-PINACA (5-OH), which exhibited a marked 260 -fold reduction in affinity for $\mathrm{hCB}_{1}$.

Overall, shifts in affinity for $\mathrm{hCB}_{2}$ receptors were less than those observed for $\mathrm{hCB}_{1}$ receptors for all compounds except 5F-APINACA, which exhibited roughly equivalent shifts for both receptors. Likewise, reductions in affinity for $\mathrm{CB}_{2}$ 
A

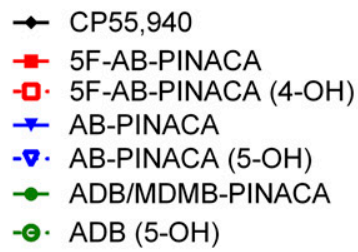

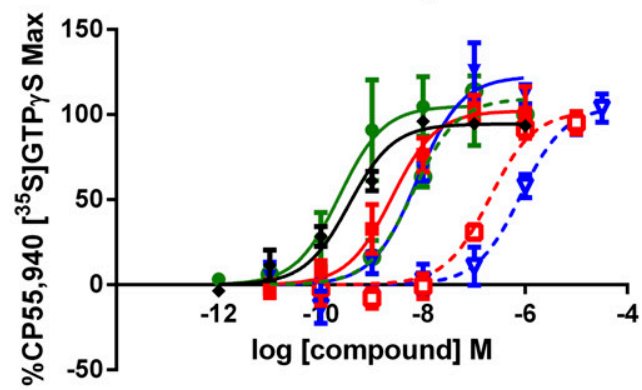

D

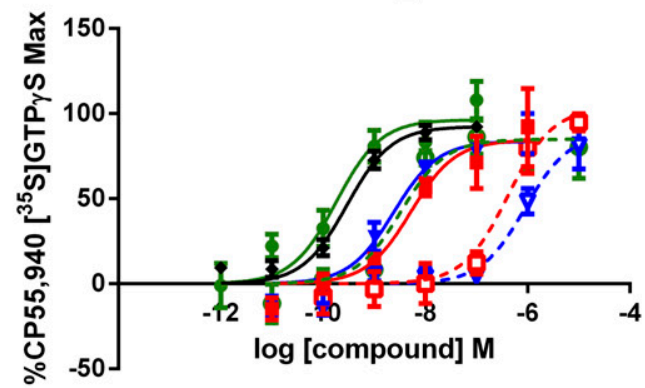

B

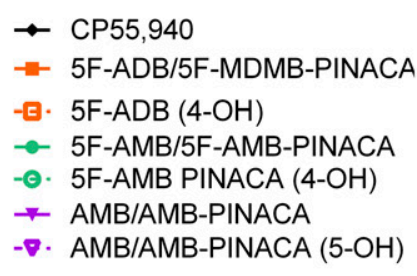

- - AMB/AMB-PINACA $(5-\mathrm{OH})$

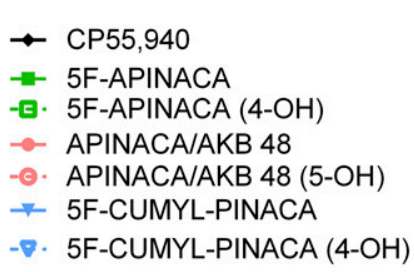

$-\nabla \cdot 5 F-C U M Y L-P I N A C A(4-O H)$
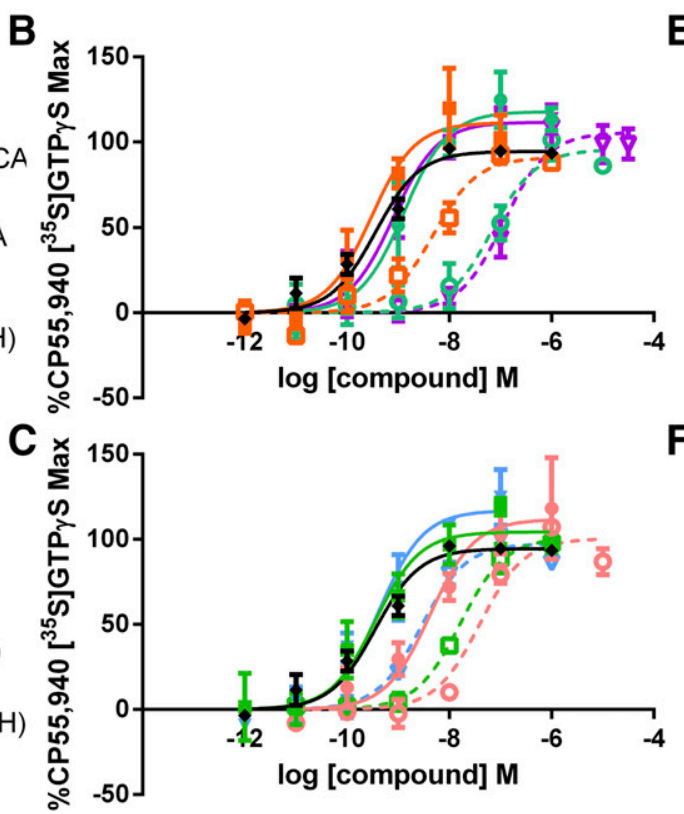

E

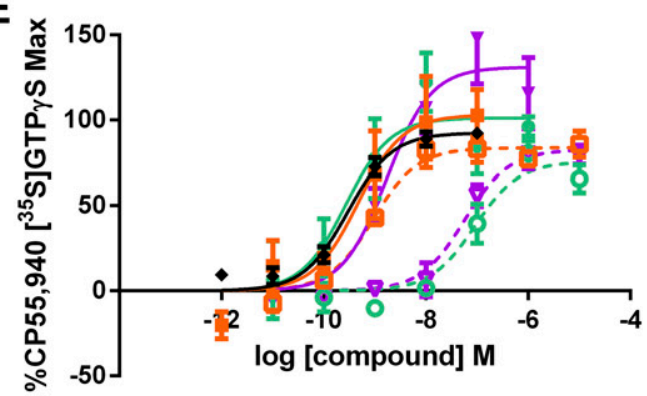

$F$

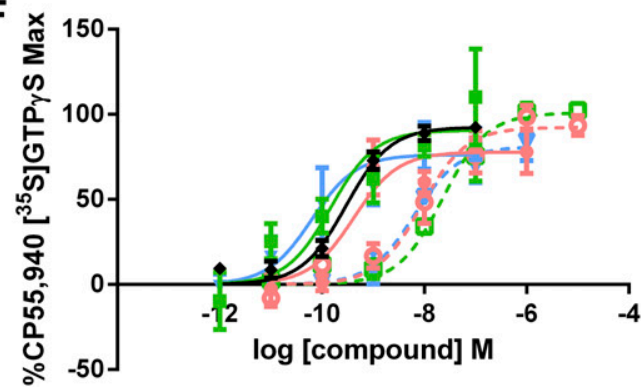

Fig. 3. Stimulation of $\left[{ }^{35} \mathrm{~S}\right] \mathrm{GTP} \gamma \mathrm{S}$ binding in $\mathrm{hCB}_{1}(\mathrm{~A}-\mathrm{C})$ and $\mathrm{hCB}_{2}(\mathrm{D}-\mathrm{F})$ expressing HEK293 cell membranes. Membranes were incubated with $30 \mu \mathrm{M}$ GDP and $0.1-0.12 \mathrm{nM}\left[{ }^{35} \mathrm{~S}\right] \mathrm{GTP} \gamma \mathrm{S}$ for 1 hour at $30^{\circ} \mathrm{C}$. Parent compound displacement curves are depicted as solid lines and their hydroxylated metabolites are depicted as dashed lines of the same color. Stimulation curves were calculated with bottom constrained to 0 . Each data point represents the mean and S.E. of at least $N=3$ experiments performed in duplicate.

receptors for 4-OH and 5-OH pentyl chain metabolites of JWH-018 and JWH-073 were also reported (Rajasekaran et al., 2013). Specifically, the JWH-018 (5-OH) metabolite exhibited an 8-fold rightward shift and the JWH-018 (4-OH) metabolite exhibited a 15 -fold rightward shift in affinity for $\mathrm{CB}_{2}$ receptors. The JWH-073 (5-OH) metabolite exhibited a 10-fold shift, whereas only a 3-fold shift was observed for the JWH-073 (4-OH) metabolite, suggesting that the location of the hydroxy group on the pentyl chain does not confer changes in affinity for $\mathrm{CB}_{2}$ equally across different structures.

Most of the parent compounds exhibited efficacy equal to that of CP55,940 with a few compounds exhibiting greater efficacy at $\mathrm{hCB}_{1}$ (AB-PINACA) or $\mathrm{hCB}_{2}$ (AMB-PINACA). This is in contrast to THC which was previously reported to exhibit partial agonism (less efficacy than CP55,940) at both $\mathrm{hCB}_{1}$ and $\mathrm{hCB}_{2}$ under the same assay conditions (Gamage et al., 2018). Except for AMB-PINACA (5-OH), all the hydroxylated metabolites retained the same level of efficacy as the parent compound in $\left.{ }^{35} \mathrm{~S}\right] \mathrm{GTP} \gamma \mathrm{S}$ binding at $\mathrm{hCB}_{1}$ and $\mathrm{hCB}_{2}$. It had been previously reported that the JWH-073 (5-OH) hydroxypentyl metabolite had reduced efficacy compared with the parent compound, with an approximately $50 \%$ reduction in ${ }^{35}$ S $]$ GTP $\gamma$ S binding (Brents et al., 2012). However, the
JWH-018 (5-OH) hydroxypentyl metabolite was reported to retain the same level of efficacy in $\left[{ }^{35} \mathrm{~S}\right] \mathrm{GTP} \gamma \mathrm{S}$ binding (Brents et al., 2011). Further, 4-OH and 5-OH pentyl metabolites of APICA and ADB-PINACA retained efficacy at $\mathrm{CB}_{1}$ and $\mathrm{CB}_{2}$ receptors (Longworth et al., 2017). Therefore, hydroxylation does not seem to impact the efficacy of most synthetic cannabinoids. Considering the metabolites retained efficacy equal to that of CP55,940, and previously THC had been shown to exhibit less efficacy than CP55,940 and other synthetic cannabinoids in the same cannabinoid receptor HEK293 membranes (Gamage et al., 2018), these data suggest that synthetic cannabinoid metabolites could continue to exert effects greater than those of THC.

Although there was strong positive correlation between the parent and metabolite $\mathrm{CB}_{2} / \mathrm{CB}_{1} \mathrm{~K}_{\mathrm{i}}$ selectivity ratios (i.e., selectivity for $\mathrm{hCB}_{2}$ increased for all but one hydroxylated compound), it was not observed for $\mathrm{CB}_{2} / \mathrm{CB}_{1} \mathrm{EC}_{50}$ selectivity ratios $(P=0.73)$, suggesting that the effects of hydroxylation on potency between $\mathrm{hCB}_{1}$ and $\mathrm{hCB}_{2}$ were less systematic. Additionally, when averaging the relative shifts in potency at $\mathrm{hCB}_{1}$ and $\mathrm{hCB}_{2}$, there was a trend for hydroxylation to produce greater reductions in potency at $\mathrm{hCB}_{2}$ receptors in comparison with $\mathrm{hCB}_{1}$ receptors. This was not statistically 
TABLE 2

Potency and efficacy of synthetic cannabinoids and metabolites in agonist-stimulated $\left[{ }^{35} \mathrm{~S}\right] \mathrm{GTP} \gamma \mathrm{S}$ binding in hCB $\mathrm{HEK}_{1} 93$ membranes

\begin{tabular}{|c|c|c|c|c|c|c|c|}
\hline Compound & $\begin{array}{l}\mathrm{pEC}_{50} \\
\pm \mathrm{S} . \mathrm{E}\end{array}$ & $\begin{array}{l}\mathrm{pEC}_{50} \\
95 \% \mathrm{CI}\end{array}$ & $\mathrm{EC}_{50}$ & $\begin{array}{l}\mathrm{E}_{\max } \\
\pm \mathrm{S} . \mathrm{E}\end{array}$ & $\begin{array}{c}\mathrm{E}_{\max } \\
95 \% \mathrm{CI}\end{array}$ & $\begin{array}{l}\mathrm{hCB}_{2} / \\
\mathrm{hCB}_{1} \\
\mathrm{EC}_{50}\end{array}$ & $\begin{array}{c}\text { Metabolite/Parent } \\
\text { EC }_{50}\end{array}$ \\
\hline \multicolumn{8}{|c|}{$n M$} \\
\hline CP55,940 & $9.45 \pm 0.0999$ & $9.25-9.64$ & 0.359 & $94.5 \pm 3.23$ & $88.1-101$ & 0.8 & \\
\hline 5F-AB-PINACA & $8.61 \pm 0.173$ & $8.24-8.98$ & 2.45 & $102 \pm 6.55$ & $88.3-116$ & 2.1 & 82.9 \\
\hline 5F-AB-PINACA (4-OH) & $6.69 \pm 0.135$ & $6.41-6.97$ & 203 & $102 \pm 6.34$ & $88.7-115$ & 2.0 & \\
\hline AB-PINACA & $8.12 \pm 0.134$ & $7.83-8.4$ & 7.63 & $122 \pm 7$ & 108-137 & 0.3 & 107.1 \\
\hline AB-PINACA (5-OH) & $6.09 \pm 0.153$ & $5.78-6.4$ & 817 & $105 \pm 7.34$ & $89.7-120$ & 1.1 & \\
\hline ADB/MDMB-PINACA & $9.63 \pm 0.27$ & $9.06-10.2$ & 0.235 & $105 \pm 10.5$ & $82.8-127$ & 0.8 & 27.5 \\
\hline ADB/MDMB-PINACA (5-OH) & $8.19 \pm 0.13$ & $7.92-8.46$ & 6.46 & $110 \pm 5.91$ & $97.2-122$ & 0.5 & \\
\hline 5F-ADB/5F-MDMB-PINACA & $9.53 \pm 0.22$ & $9.07-10$ & 0.294 & $111 \pm 9.14$ & $92-131$ & 1.6 & 16.2 \\
\hline $5 \mathrm{~F}-\mathrm{ADB}(4-\mathrm{OH})$ & $8.32 \pm 0.157$ & $8-8.64$ & 4.77 & $90.9 \pm 5.65$ & $79.4-102$ & 0.2 & \\
\hline 5F-AMB/5F-AMB-PINACA & $8.89 \pm 0.201$ & $8.46-9.31$ & 1.3 & $118 \pm 8.7$ & $99.4-136$ & 0.2 & 51.5 \\
\hline 5F-AMB PINACA (4-OH) & $7.18 \pm 0.2$ & $6.77-7.58$ & 66.9 & $95.6 \pm 8.02$ & $79.3-112$ & 1.3 & \\
\hline AMB/AMB-PINACA & $9.1 \pm 0.169$ & $8.74-9.45$ & 0.804 & $112 \pm 6.73$ & $97.4-126$ & 2.1 & 143.0 \\
\hline AMB/AMB-PINACA (5-OH) & $6.94 \pm 0.146$ & $6.64-7.24$ & 115 & $106 \pm 5.91$ & $93.4-118$ & 0.5 & \\
\hline 5F-APINACA & $9.44 \pm 0.212$ & $9-9.89$ & 0.359 & $104 \pm 7.1$ & $89.4-119$ & 0.4 & 45.7 \\
\hline 5 F-APINACA (4-OH) & $7.79 \pm 0.0929$ & $7.59-7.98$ & 16.4 & $101 \pm 4.29$ & $92-110$ & 1.4 & \\
\hline APINACA/AKB 48 & $8.37 \pm 0.235$ & $7.88-8.87$ & 4.24 & $112 \pm 10.2$ & $90.1-133$ & 0.1 & 9.3 \\
\hline APINACA/AKB 48 (5-OH) & $7.4 \pm 0.123$ & $7.15-7.66$ & 39.4 & $100 \pm 4.77$ & $90.6-110$ & 0.2 & \\
\hline 5F-CUMYL-PINACA & $9.37 \pm 0.188$ & $8.97-9.77$ & 0.428 & $117 \pm 8.54$ & $98.8-135$ & 0.1 & 6.6 \\
\hline 5F-CUMYL-PINACA (4-OH) & $8.55 \pm 0.107$ & $8.33-8.77$ & 2.83 & $97.4 \pm 4.09$ & $88.9-106$ & 2.2 & \\
\hline
\end{tabular}

significant $(P=0.18)$ and was largely driven by two compounds, AB-PINACA and 5F-AMB. In contrast to the binding data, in which there was a modest increase in receptor selectivity for $\mathrm{hCB}_{2}$, compounds were roughly evenly split when the effects of pentyl-hydroxylation on potency for $\mathrm{hCB}_{1}$ were compared with $\mathrm{hCB}_{2}$. Previously, the ADB-PINACA (5$\mathrm{OH}$ ) metabolite exhibited greater selectivity for $\mathrm{CB}_{2}$ (11-fold) compared with the parent (0.5-fold) in functional studies (Longworth et al., 2017). In the present study, although most compounds exhibited greater reductions in potency at $\mathrm{hCB}_{2}$ receptors in comparison with $\mathrm{hCB}_{1}$ receptors, 5F-ADB exhibited a 1.6-fold selectivity for $\mathrm{CB}_{1}$, whereas the metabolite (4-OH) was 5-fold more selective for $\mathrm{hCB}_{2}$ in the functional assay. Thus, pentyl hydroxylation does not affect all structures in the same way.
In contrast to the pharmacological properties of synthetic cannabinoid metabolites, their toxicological properties remain less well characterized, though some work has been done. An hydroxypentyl metabolite of JWH-018 was reported to reduce cell viability - an effect that was not observed for the parent compound - via a noncannabinoid mechanism (Couceiro et al., 2016). Therefore, while assessment of synthetic cannabinoid metabolite pharmacology in the current study provides information regarding the potential for active metabolites to retain activity at cannabinoid receptors and contribute to the overall cannabinoid pharmacological profile in vivo, questions remain regarding how toxicity is mediated by noncannabinoid receptor mechanisms for these compounds and/or their metabolites. Numerous synthetic cannabinoids have now been implicated in deaths, including those characterized in the

TABLE 3

Potency and efficacy of synthetic cannabinoids and metabolites in agonist-stimulated $\left[{ }^{35} \mathrm{~S}\right] \mathrm{GTP} \gamma \mathrm{S}$ binding in hCB $\mathrm{HEK}_{2} 93$ membranes

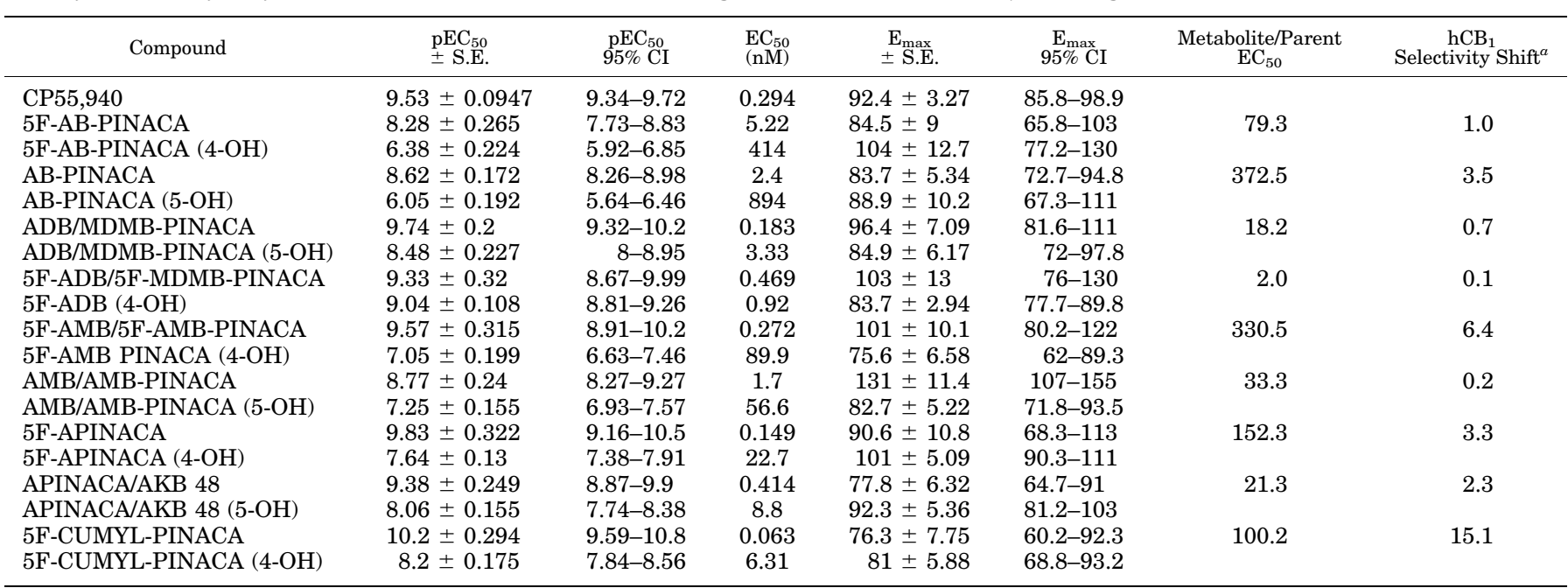

${ }^{a}\left(\right.$ Metabolite/parent $\mathrm{EC}_{50} \mathrm{hCB}_{1}$ ratio)/(metabolite/parent $\mathrm{EC}_{50} \mathrm{hCB}_{2}$ ratio). Less than $1=$ greater reduction in potency for hCB ${ }_{1}$, greater than $1=$ greater reduction in potency for ${ }_{\mathrm{hCB} 2}$. 
present study, e.g., 5F-AMB (Shanks and Behonick, 2016), 5FADB (Hasegawa et al., 2015; Angerer et al., 2017; Kusano et al., 2018), and 5F-APINACA (Hess et al., 2015). Despite detection and implication in these deaths and others, the contribution of the parent and/or metabolite is unknown as are the mechanisms.

Characterization of enzymes involved in synthetic cannabinoid metabolism and how that may relate to their toxicity is currently being investigated. Major cytochrome P450 isoforms involved in metabolism of JWH-018 and AM2201 include CYP2C9 and CYP1A2 (Chimalakonda et al., 2012). CYP3A4 was reported to be the major enzyme mediating oxidative metabolism of AKB-48 (Holm et al., 2015). Variation in metabolism of synthetic cannabinoids by polymorphisms in cytochrome P450 enzymes (e.g., CYP2C9) has been offered as a possible explanation for variance in toxicological effects of synthetic cannabinoids, specifically JWH-018 (Patton et al., 2018). In some cases, the metabolite exhibits toxicity not observed with the parent (Couceiro et al., 2016). Further, toxicity may not even involve cannabinoid receptor mechanisms, as metabolism of CUMYL-4CN-BINACA has been reported to liberate cyanide (Åstrand et al., 2018; Kevin et al., 2018). Thus synthetic cannabinoids could produce toxicity by a multitude of ways. Glucuronidation is the next step in biologic inactivation of synthetic cannabinoids leading to their excretion in urine (Möller et al., 2011). It was reported that glucuronidation of the 5-hydroxypentyl JWH-018 metabolite retains affinity, albeit much lower, for the $\mathrm{CB}_{1}$ receptor, but acts as an antagonist rather than an agonist (Seely et al., 2012). It may be then that intermediate metabolic oxidative products contribute to pharmacological effects but following glucuronidation lose their agonist activity, though this has yet to be established for other synthetic cannabinoids.

In summary, pentyl hydroxylation reduces the affinity of the synthetic cannabinoids at both $\mathrm{hCB}_{1}$ and $\mathrm{hCB}_{2}$ receptors. The greater reduction in affinity at $\mathrm{hCB}_{1}$ effectively increases the binding selectivity for $\mathrm{hCB}_{2}$ receptors. Importantly, the synthetic cannabinoid hydroxypentyl metabolites retain the same level of efficacy, which is greater than THC's (Gamage et al., 2018). These metabolites probably contribute to the observed in vivo pharmacology of synthetic cannabinoids and the differences in subjective intensity compared with that of cannabis (Griffiths et al., 2010; Barratt et al., 2013). Further studies exploring the toxicological properties of synthetic cannabinoids and their metabolites are needed to better understand the mechanisms through which they are producing life-threatening effects.

\section{Authorship Contributions}

Participated in research design: Gamage, Farquhar, McKinnie, Trudell, Wiley, Thomas.

Conducted experiments: Gamage, Farquhar.

Contributed new reagents or analytic tools: Trudell, McKinnie.

Performed data analysis: Gamage, Farquhar.

Wrote or contributed writing to the manuscript: Gamage, Farquhar, McKinnie, Kevin, McGregor, Trudell, Wiley, Thomas.

\section{References}

Andersson M, Diao X, Wohlfarth A, Scheidweiler KB, and Huestis MA (2016) Metabolic profiling of new synthetic cannabinoids AMB and 5F-AMB by human hepatocyte and liver microsome incubations and high-resolution mass spectrometry. Rapid Commun Mass Spectrom 30:1067-1078.

Angerer V, Jacobi S, Franz F, Auwärter V, and Pietsch J (2017) Three fatalities associated with the synthetic cannabinoids 5F-ADB, 5F-PB-22, and AB-CHMINACA. Forensic Sci Int 281:e9-e15.
Astrand A, Vikingsson S, Lindstedt D, Thelander G, Gréen H, Kronstrand R, and Wohlfarth A (2018) Metabolism study for CUMYL-4CN-BINACA in human hepatocytes and authentic urine specimens: free cyanide is formed during the main metabolic pathway. Drug Test Anal 10:1270-1279.

Banister SD and Connor M (2018) The chemistry and pharmacology of synthetic cannabinoid receptor agonists as new psychoactive substances: origins. Handb Exp Pharmacol DOI: 10.1007/164_2018_143 [published ahead of print].

Barceló B, Pichini S, López-Corominas V, Gomila I, Yates C, Busardò FP, and Pellegrini $\mathrm{M}$ (2017) Acute intoxication caused by synthetic cannabinoids 5FADB and MMB-2201: a case series. Forensic Sci Int 273:e10-e14.

Barratt MJ, Cakic V, and Lenton S (2013) Patterns of synthetic cannabinoid use in Australia. Drug Alcohol Rev 32:141-146.

Berg T, Kaur L, Risnes A, Havig SM, and Karinen R (2016) Determination of a selection of synthetic cannabinoids and metabolites in urine by UHPSFC-MS/MS and by UHPLC-MS/MS. Drug Test Anal 8:708-722.

Berry-Cabán CS, Kleinschmidt PE, Rao DS, and Jenkins J (2012) Synthetic cannabinoid and cathinone use among US soldiers. US Army Med Dep J Oct-Dec:19-24

Brents LK, Gallus-Zawada A, Radominska-Pandya A, Vasiljevik T, Prisinzano TE, Fantegrossi WE, Moran JH, and Prather PL (2012) Monohydroxylated metabolites of the K2 synthetic cannabinoid JWH-073 retain intermediate to high cannabinoid 1 receptor (CB1R) affinity and exhibit neutral antagonist to partial agonist activity. Biochem Pharmacol 83:952-961.

Brents LK, Reichard EE, Zimmerman SM, Moran JH, Fantegrossi WE, and Prather PL (2011) Phase I hydroxylated metabolites of the K2 synthetic cannabinoid JWH018 retain in vitro and in vivo cannabinoid 1 receptor affinity and activity. PLoS One 6:e21917.

Cannaert A, Franz F, Auwärter V, and Stove CP (2017) Activity-based detection of consumption of synthetic cannabinoids in authentic urine samples using a stable cannabinoid reporter system. Anal Chem 89:9527-9536.

Cannaert A, Storme J, Franz F, Auwärter V, and Stove CP (2016) Detection and activity profiling of synthetic cannabinoids and their metabolites with a newly developed bioassay. Anal Chem 88:11476-11485.

Carlier J, Diao X, and Huestis MA (2018) Synthetic cannabinoid BB-22 (QUCHIC): human hepatocytes metabolism with liquid chromatography-high resolution mass spectrometry detection. J Pharm Biomed Anal 157:27-35.

Castaneto MS, Scheidweiler KB, Gandhi A, Wohlfarth A, Klette KL, Martin TM, and Huestis MA (2015) Quantitative urine confirmatory testing for synthetic cannabinoids in randomly collected urine specimens. Drug Test Anal 7:483-493.

Chimalakonda KC, Seely KA, Bratton SM, Brents LK, Moran CL, Endres GW, James LP, Hollenberg PF, Prather PL, Radominska-Pandya A, et al. (2012) Cytochrome P450-mediated oxidative metabolism of abused synthetic cannabinoids found in K2/spice: identification of novel cannabinoid receptor ligands. Drug Metab Dispos 40:2174-2184

Couceiro J, Bandarra S, Sultan H, Bell S, Constantino S, and Quintas A (2016) Toxicological impact of JWH-018 and its phase I metabolite N-(3-hydroxypentyl) on human cell lines. Forensic Sci Int 264:100-105.

Every-Palmer S (2011) Synthetic cannabinoid JWH-018 and psychosis: an explorative study. Drug Alcohol Depend 117:152-157.

Fantegrossi WE, Moran JH, Radominska-Pandya A, and Prather PL (2014) Distinct pharmacology and metabolism of K2 synthetic cannabinoids compared to $\Delta(9)$ THC: mechanism underlying greater toxicity? Life Sci 97:45-54

Funada M and Takebayashi-Ohsawa M (2018) Synthetic cannabinoid AM2201 in duces seizures: involvement of cannabinoid $\mathrm{CB}_{1}$ receptors and glutamatergic transmission. Toxicol Appl Pharmacol 338:1-8.

Gamage TF, Farquhar CE, Lefever TW, Marusich JA, Kevin RC, McGregor IS, Wiley JL, and Thomas BF (2018) Molecular and behavioral pharmacological characterization of abused synthetic cannabinoids MMB- and MDMB-FUBINACA, MN-18, NNEI, CUMYL-PICA, and 5-Fluoro-CUMYL-PICA. J Pharmacol Exp Ther 365: $437-446$.

Griffiths P, Sedefov R, Gallegos A, and Lopez D (2010) How globalization and market innovation challenge how we think about and respond to drug use: 'Spice' a case study. Addiction 105:951-953.

Gunderson EW, Haughey HM, Ait-Daoud N, Joshi AS, and Hart CL (2012) "Spice" and "K2" herbal highs: a case series and systematic review of the clinical effects and biopsychosocial implications of synthetic cannabinoid use in humans. Am $J$ Addict 21:320-326.

Hasegawa K, Wurita A, Minakata K, Gonmori K, Yamagishi I, Nozawa H, Watanabe $\mathrm{K}$, and Suzuki O (2015) Identification and quantitation of 5-fluoro-ADB, one of the most dangerous synthetic cannabinoids, in the stomach contents and solid tissues of a human cadaver and in some herbal products. Forensic Toxicol 33:112-121.

Hess C, Stockhausen S, Kernbach-Wighton G, and Madea B (2015) Death due to diabetic ketoacidosis: induction by the consumption of synthetic cannabinoids? Forensic Sci Int 257:e6-e11.

Holm NB, Nielsen LM, and Linnet K (2015) CYP3A4 mediates oxidative metabolism of the synthetic cannabinoid AKB-48. AAPS J 17:1237-1245.

Kendall DA and Yudowski GA (2017) Cannabinoid receptors in the central nervous system: their signaling and roles in disease. Front Cell Neurosci 10:294.

Kevin RC, Kovach AL, Lefever TW, Gamage TF, Wiley JL, McGregor IS, and Thomas BF (2018) Toxic by design? Formation of thermal degradants and cyanide from carboxamide-type synthetic cannabinoids CUMYL-PICA, 5F-CUMYL-PICA, AMBFUBINACA, MDMB-FUBINACA, NNEI, and MN-18 during exposure to high temperatures. Forensic Toxicol 1-10.

Kevin RC, Lefever TW, Snyder RW, Patel PR, Fennell TR, Wiley JL, McGregor IS, and Thomas BF (2017) In vitro and in vivo pharmacokinetics and metabolism of synthetic cannabinoids CUMYL-PICA and 5F-CUMYL-PICA. Forensic Toxicol 35:333-347.

Kusano M, Zaitsu K, Taki K, Hisatsune K, Nakajima J, Moriyasu T, Asano T, Hayashi Y, Tsuchihashi H, and Ishii A (2018) Fatal intoxication by 5F-ADB and diphenidine: detection, quantification, and investigation of their main metabolic pathways in humans by LC/MS/MS and LC/Q-TOFMS. Drug Test Anal 10: $284-293$. 
Longworth M, Connor M, Banister SD, and Kassiou M (2017) Synthesis and pharmacological profiling of the metabolites of synthetic cannabinoid drugs APICA STS-135, ADB-PINACA, and 5F-ADB-PINACA. ACS Chem Neurosci 8:1673-1680.

Malyshevskaya O, Aritake K, Kaushik MK, Uchiyama N, Cherasse Y, KikuraHanajiri R, and Urade Y (2017) Natural ( $\Delta^{9}$-THC) and synthetic (JWH-018) cannabinoids induce seizures by acting through the cannabinoid $\mathrm{CB}_{1}$ receptor. Sci Rep 7:10516.

McKinnie RJ, Darweesh T, Zito PA, Shields TJ, and Trudell ML (2018) Synthesis of the 5-Fluoro-4-hydroxypentyl side chain metabolites of synthetic cannabinoids 5FAPINACA and CUMYL-5F-PINACA. Synthesis 50:4683-4689.

Mogler L, Franz F, Wilde M, Huppertz LM, Halter S, Angerer V, Moosmann B, and Auwärter V (2018) Phase I metabolism of the carbazole-derived synthetic cannabinoids EG-018, EG-2201, and MDMB-CHMCZCA and detection in human urine samples. Drug Test Anal 10:1417-1429.

Möller I, Wintermeyer A, Bender K, Jübner M, Thomas A, Krug O, Schänzer W, and Thevis M (2011) Screening for the synthetic cannabinoid JWH-018 and its major metabolites in human doping controls. Drug Test Anal 3:609-620.

Patton AL, Seely KA, Yarbrough AL, Fantegrossi W, James LP, McCain KR, Fujiwara R, Prather PL, Moran JH, and Radominska-Pandya A (2018) Altered metabolism of synthetic cannabinoid JWH-018 by human cytochrome P450 2C9 and variants. Biochem Biophys Res Commun 498:597-602.

Rajasekaran M, Brents LK, Franks LN, Moran JH, and Prather PL (2013) Human metabolites of synthetic cannabinoids JWH-018 and JWH-073 bind with high af finity and act as potent agonists at cannabinoid type-2 receptors. Toxicol Appl Pharmacol 269:100-108.

Richter LHJ, Maurer HH, and Meyer MR (2017) New psychoactive substances: studies on the metabolism of XLR-11, AB-PINACA, FUB-PB-22, 4-methoxy- $\alpha$-PVP, 25-I-NBOMe, and meclonazepam using human liver preparations in comparison to primary human hepatocytes, and human urine. Toxicol Lett 280:142-150.

Seely KA, Brents LK, Radominska-Pandya A, Endres GW, Keyes GS, Moran JH, and Prather PL (2012) A major glucuronidated metabolite of JWH-018 is a neutra antagonist at CB1 receptors. Chem Res Toxicol 25:825-827.

Shanks KG and Behonick GS (2016) Death after use of the synthetic cannabinoid 5F-AMB. Forensic Sci Int 262:e21-e24.
Svízenská I, Dubový P, and Sulcová A (2008) Cannabinoid receptors 1 and 2 (CB1 and CB2), their distribution, ligands and functional involvement in nervous system structures--a short review. Pharmacol Biochem Behav 90:501-511.

Tai S and Fantegrossi WE (2017) Pharmacological and toxicological effects of synthetic cannabinoids and their metabolites. Curr Top Behav Neurosci 32:249-262.

Takayama T, Suzuki M, Todoroki K, Inoue K, Min JZ, Kikura-Hanajiri R, Goda Y, and Toyo'oka T (2014) UPLC/ESI-MS/MS-based determination of metabolism of several new illicit drugs, ADB-FUBINACA, AB-FUBINACA, AB-PINACA, QUPIC, $5 F-Q U P I C$ and $\alpha$-PVT, by human liver microsome. Biomed Chromatogr 28:831-838.

Thakur GA, Nikas SP, Li C, and Makriyannis A (2005) Structural requirements for cannabinoid receptor probes. Handb Exp Pharmacol (168):209-246.

Thomas BF (2017) Interactions of cannabinoids with biochemical substrates. Subst Abuse 11:1178221817711418.

Thomas BF, Lefever TW, Cortes RA, Grabenauer M, Kovach AL, Cox AO, Patel PR, Pollard GT, Marusich JA, Kevin RC, et al. (2017) Thermolytic degradation of synthetic cannabinoids: chemical exposures and pharmacological consequences. J Pharmacol Exp Ther 361:162-171.

Trecki J, Gerona RR, and Schwartz MD (2015) Synthetic cannabinoid-related illnesses and deaths. $N$ Engl J Med 373:103-107.

Usui K, Fujita Y, Kamijo Y, Kokaji T, and Funayama M (2018) Identification of 5-fluoro ADB in human whole blood in four death cases. J Anal Toxicol 42:e21-e25.

Vandrey R, Dunn KE, Fry JA, and Girling ER (2012) A survey study to characterize use of Spice products (synthetic cannabinoids). Drug Alcohol Depend 120:238-241.

Wiley JL, Marusich JA, Huffman JW, Balster RL, and Thomas BF (2011) Hijacking of basic research: the case of synthetic cannabinoids. Methods Rep RTI Press 2011.

Wohlfarth A, Castaneto MS, Zhu M, Pang S, Scheidweiler KB, Kronstrand R, and Huestis MA (2015) Pentylindole/pentylindazole synthetic cannabinoids and their 5-Fluoro analogs produce different primary metabolites: metabolite profiling for AB-PINACA and 5F-AB-PINACA. AAPS J 17:660-677.

Address correspondence to: Dr. Brian F. Thomas, RTI International, 3040 Cornwallis Rd., Research Triangle Park, NC 27709. E-mail: bft@rti.org 